\title{
Correction to: Nationwide epidemiology of carbapenem resistant Klebsiella pneumoniae isolates from Greek hospitals, with regards to plazomicin and aminoglycoside resistance
}

Irene Galani ${ }^{1,3^{*}+}$, Konstantina Nafplioti $^{1 \dagger}$, Panagiota Adamou ${ }^{1}$, llias Karaiskos ${ }^{2}$, Helen Giamarellou ${ }^{2}$, Maria Souli ${ }^{1}$ and Study Collaborators

\section{Correction to: BMC Infectious Diseases 2019 19:167 https://doi.org/10.1186/s12879-019-3801-1}

Following publication of the original article [1], the authors reported that a collaborator's name has been misspelled. Viktoria Eirini Mavromanolaki has been written by mistake Viktoria Eirini Mauromanolaki ( $u$ instead of v).

\footnotetext{
Author details

'Infectious Diseases Laboratory, 4th Department of Internal Medicine, National and Kapodistrian University of Athens, Faculty of Medicine, Athens, Greece. ${ }^{2} 6$ th Department of Internal Medicine, Hygeia Hospital, Athens, Greece. "University General Hospital "ATTIKON", Rimini 1, 12462 Chaidari, Greece.
}

Received: 26 February 2019 Accepted: 26 February 2019

Published online: 07 March 2019

\section{Reference}

1. Galani et al. (2019) Nationwide epidemiology of carbapenem resistant Klebsiella pneumoniae isolates from Greek hospitals, with regards to plazomicin and aminoglycoside resistance (2019) 19:167 doi: https://doi.org/10.1186/s12879-019-3801-1.

\footnotetext{
* Correspondence: egalani@med.uoa.gr

† Irene Galani and Konstantina Nafplioti contributed equally to this work.

${ }^{1}$ Infectious Diseases Laboratory, 4th Department of Internal Medicine,

National and Kapodistrian University of Athens, Faculty of Medicine, Athens, Greece

${ }^{3}$ University General Hospital "ATTIKON", Rimini 1, 12462 Chaidari, Greece

Full list of author information is available at the end of the article
}

(c) The Author(s). 2019 Open Access This article is distributed under the terms of the Creative Commons Attribution 4.0 International License (http://creativecommons.org/licenses/by/4.0/), which permits unrestricted use, distribution, and reproduction in any medium, provided you give appropriate credit to the original author(s) and the source, provide a link to the Creative Commons license, and indicate if changes were made. The Creative Commons Public Domain Dedication waiver (http://creativecommons.org/publicdomain/zero/1.0/) applies to the data made available in this article, unless otherwise stated. 